\title{
CHEMICAL ANALYSIS AND FATTY ACID COMPOSITION OF THE CHICORY PLANTS (CICHORIUM INTYBUS L.) BY GC-MS
}

\author{
Nursel Kama ${ }^{a}$ Gulsah Saydan Kanberoglu ${ }^{a^{*}}$ \\ Department of Chemistry, Van Yuzuncu Yil University, Van, Turkey \\ gskanberoglu@yyu.edu.tr (*correspondingauthor)
}

\begin{abstract}
In this paper, chemical composition and fatty acid composition of the Cichorium intybus L. plants were investigated. For this aim, Cichorium intybus L. plant was powdered and analyzed. Soxhelet extraction method was applied and fatty acid composition of Cichorium intybus L. plants powder was determined by GC-MS. Lignin, cellulose, moisture, ash, fat and extractives content of the plant were determined as $14.9 \%, 30.0 \%, 5.4 \%, 10.7 \%, 2.5 \%$ and $\% 6.8$ respectively. Linoleic acid was determined as major fatty acid of the plant (31.8\%). The polyunsaturated fatty acid content of the plant (58.9\%) was higher than saturated fatty acid content (41.2). The monounsaturated fatty acid was not determined in the samples. This study suggested that Cichorium intybus L. plants could be considered as a healthy fat source due to high polyunsaturated content.
\end{abstract}

Keywords: Cichorium intybus L., chemical analysis, GC-MS

\section{Introduction}

Chicory (Cichorium intybus L.) is a frequently known vegetable in the Mediterranean region and also a member of the Asteraceae family $[1,2]$. The Asteraceae family cichorium type's flower plants are prevalently called chicory. Cichorium intybus, originated from Eurasia, is a bushy long-lasting plant with flowers of blue, white, or pink-blue, whose branching stem can extend $170 \mathrm{~cm}$. Other noted chicories are blue sailors, succory and coffeeweed. C. intybus is an acknowledged weed, while C. endivia is a rare one, both are widely grown species in Lithuania. The natural habitats of $\mathrm{C}$. intybus are urban areas, waysides, railways, and waste storage areas. Its flowering period is from June to October [3].

In history, Egyptians cultivated chicory as a therapeutic plant, replacement for coffee, and 
vegetable produce and was rarely utilized as animal feed. In the $1970 \mathrm{~s}$, it was found out that the C. intybus root comprises up to $40 \%$ inulin, which has an insignificant effect on blood sugar and hence is appropriate for diabetes [4]. The chicory roots have been grown in Europe, then they were roasted and utilized as an alternative to coffee and additives for ages [5].

In addition to that, chicory is both a food and a medicinal plant, grown in many parts of the world, that has been used for the treatment of many diseases because of digestive, diuretic, laxative and anti-anaemia effects in global scale [6, 7].

In recent years, many studies on the Cichorium intybus L. family leafy vegetables indicated that their popularity is because of their essential food elements (i.e. polyphenols, vitamins, minerals, and biologically active elements) and health benefits.

$[8,9,10,11,12]$.

For a long time, chicory has been a valuable plant in medicinal use, as a natural herbal liver tonic and digestive. The studies have reported that chicory root extracts purify improve blood and also help to remove oil concentrations and toxins in the vessels. Chicory roots improve the remedies in liver enlargement, jaundice, rheumatism and gout [13]. Aside from the mentioned benefits, chicory roots and leaves are also used for the following:appetizers, digestives, cholagogues, depuratives, diuretics, hypoglycaemics, laxatives and tonics $[14,15,16,17,18$, 19].

The chicory flowers are utilized as treatments/remedies for stomach-enteritis, sinus problems, cuts and contusions even though the roots are the utmost active part in medical use. [19]. Moreover, chicory juice is believed to be a traditional treatment for uterus cancer and tumors $[20,21,22,23,24]$. In the biosphere, which is also called the universe of living beings, almost $27 \times 10^{10}$ tons of carbon are dependent on living organisms and more than $99 \%$ of it is found in botanical materials. Almost $40 \%$ of the carbon found in plants is composed of cellulose [25].

Plant and animal wastes containing lignin and cellulose can be defined as biomass. These are trees, shrubberies, forest wastes, woody and herbaceous plants, animal droppings, solid wastes and garbage, industrial wastes, waste water and human wastes [26, 27, 28, 29, 30]. Biomass is considered to be all organic-based substances living on earth, these (plants, algae, etc.) store solar energy and produce biomass continuously by photosynthesis [31].

The structures of lignocellulosic materials consist of holocellulose (cellulose-hemicellulose) and lignin. The use of these substances as a renewable energy source is very important. Because, since a continuous cycle occurs through photosynthesis, the resource is not exhausted and does not affect the increase of carbon dioxide in the atmosphere. Here, carbon dioxide and water are reduced to combustible compounds, and the energy required for these reactions is provided by solar radiation. Solar energy accumulated by plants in this way is shown as one of the important alternative energy sources [32].

The presence of lipids in plant cells is in small amounts and mostly in the cell membranes. Plant fatty acids are composed of a few 16-carbon or 18-carbon length structures, and one to three double bonds [33]. The major plant lipids are the saturated fatty acids (SFAs) palmitic (C 16:0) and stearic (C 18:0) acids, the monounsaturated fatty acid (MUFA) oleic acid (C 18:1; n-9), and the polyunsaturated fatty acids (PUFAs) linoleic (C 18:2; n-6) and a-linolenic (C 18:3; n3) acids [34]. The omega-3 (n-3) PUFAs that are identified in plants have been linked with diverse health utilities regarding to maternal and child health, cardiovascular disease, and 
pleiotropic effects [35] and influences against inflammation, cancer and heart diseases [36]. Alpha-linolenic acid is the forerunner of the long chain n-3 PUFAs, such as eicosapentaenoic and docosahexaenoic acids, and it is acknowledged to be existing in many plants, including chicory [37]. Two of the fatty acids are essential for human being. One of them is linoleic acid and the other is linolenic acid. If there is no lineloic acid in the diet, it is classified as essential fatty acid in arachidonic acid. Such fatty acids are also called vitamin F, a health-friendly vitamin. Since they cannot be synthesized by human and animal organisms, they are supplemented by nutrients. If these essential fatty acids are not supplemented adequately by food, health problems such as some skin diseases, regression in growth, kidney damage and vomiting blood are encountered. The ability of people to perform many mental and physical functions is closely related to essential fatty acids [38].

Even though it is thought that chicory's being rich in polyunsaturated fatty acid causes decrease in its oxidative stability, that the level of its saturated fat content is high provides a balance in terms of oxidative stability.

This study, the fatty acids of fat obtained from lignin, cellulose, moisture, ash amount and flour of chicory plant samples, attained from various regions of Van Özalp, were determined with the GC-MS method.

\section{Materials and method}

\subsection{Material}

The nitric acid, sulfuric acid, acetone, acetic acid, sodium hydroxide, petroleum ether, $\mathrm{KOH}$, $\mathrm{MeOH}$ used in the study were obtained from the company Merck Merck (Darmstadt, Germany).

\subsection{Method}

\subsubsection{Sampling}

In this study, Chicory (Cichorium intybus L.) plant, harvested in July 2016 was obtained from the location in Özalp district of Van and dried.

\subsubsection{Grinding and sieving}

Sampling and preparation of the sample to be used for chemical analyses was performed according to TAPPI T11 m-45 standard. The sample was ground in a Willey mill (Perten instruments LM120, Sweden) and then sifted through a 40 and 60 mesh sieve. Very thin sections were siftedthrough a 60 mesh sieve and coarse sections were sifted through a 40 mesh sieve. The fractions remaining on the 60 mesh sieve were then used for analysis. The prepared samples was stored in a dark, closed and dry place.

\subsubsection{Determination of lignin}

Lignin was determined according to TAPPI T13 m-54 standard. When wood is treated with strong acids, the carbohydrates are hydrolyzed and thus, since they remain undissolved together with lignin, it is initially necessary to provide the removal of extractives using petroleum ether as the appropriate solvent. In this experiment petroleum ether was used as solvent and the extraction was carried out in a soxhelet extraction apparatus. 
Ground Cichorium intybus L. was kept for two hours in $18-20^{\circ} \mathrm{C}$, occasionally stirring after taking $1 \mathrm{gr}$ from its stalk and adding $15 \mathrm{ml}$ of $72 \% \mathrm{H}_{2} \mathrm{SO}_{4}$ in $12-15{ }^{\circ} \mathrm{C}$ It was filtered, the material was washed with distilled water and distilled water was added until it was $560 \mathrm{ml}$. Afterwards, this mixture was boiled for four hours under cooler. After the precipitation of the undissolved material, the crucible mixture with a determined porosity of 3 at $105 \pm 3{ }^{\circ} \mathrm{C}$ was filtered. The free acid residues were washed with $500 \mathrm{ml}$ of hot water, dried with crucible 3 at $105 \pm 3{ }^{\circ} \mathrm{C}$ and cooled in a desiccator to constant weighing.

\subsubsection{Determination of cellulose}

Cellulose determination was performed according to TAPPI 05-2C3 71 standard. $2 \mathrm{~g}$ were taken from Cichorium intybus L. stalk, and $10 \mathrm{ml} 40 \% \mathrm{HNO}_{3}, 40 \mathrm{ml} \mathrm{96 \%} \mathrm{ethyl} \mathrm{alcohol} \mathrm{were} \mathrm{added}$ on it and it was allowed to boil under condenser. Fatty substances are dissolved with the effect of $\mathrm{HNO}_{3}$, hemicelluloses are hydrolyzed and lignin is transformed into nitrophenolic compounds. Here alcohol, protects cellulose from $\mathrm{HNO}_{3}$. After boiling for one hour, the liquid in the flask was filtered with the help of crucible 2 and the sample remaining on the crucible was washed with a new mixture composed of $10 \mathrm{ml}$ of $\mathrm{HNO}_{3}$ and $40 \mathrm{ml}$ of ethyl alcohol. Boiling was continued again for one hour and the same procedure was repeated three times. The crucible was then filtered, the sample remaining on the crucible was washed with hot water, dried at 105 $\pm 3{ }^{\circ} \mathrm{C}$ and after being cooled in a desiccator, brought to constant weighing.

\subsubsection{Ash determination}

Ash determination was made according to TAPPI T211 om- 85 standard. High temperature resistant crucibles were brought to constant weighing at $575 \pm 25{ }^{\circ} \mathrm{C}$ and $2 \mathrm{~g}$ of chicory (Cichorium intybus L.) stems were taken and placed in crucibles kept at $575 \pm 25^{\circ} \mathrm{C}$ in muffle furnace for 2 hours and then cooled to constant weighing.

\subsubsection{Determination of moisture}

$1 \mathrm{~g}$ was taken from the milled chicory (Cichorium intybus L.) stem and placed in nickel plates and dried at $105{ }^{\circ} \mathrm{C}$ for 2 hours. Then it was cooled in the desiccator and weighed and its humidity rate was found.

\subsubsection{Extractives}

After passing through a 40 mesh sieve, and $10 \mathrm{~g}$ of the remaining sample on a 60 mesh sieve was put in the filter paper, the extraction crucible was placed in the cartridge. This crucible was then placed in the Soxhlet extraction device and the petroleum ether and ground Cichorium intybus L stem in the crucible were extracted for 4 hours.

\subsubsection{Determination of oil}

$10 \mathrm{~g}$ was taken from the milled sample and placed in the extraction crucible. This crucible was then placed in the Soxhlet extraction device and the petroleum ether and Cichorium intybus L. stem flour in the crucible were extracted for 6 hours. The extraction temperature was adjusted to siphon every 10 minutes. At the end of the process, the amount of fat was determined by evaporating $\left(40^{\circ}-60^{\circ}\right)$ it in the liquid in the volumetric flask. 


\subsubsection{The chemical analysis of chicory (Cichorium intybus L.) plant, the analysis and characterization of the obtained fat with GS-MS}

The derivatization reaction was used to convert fatty acids to methyl esters (FAME) to identify them by GC-MS. FAME was prepared by transesterification of hexane or petroleum ether extracts in basic medium and converted to volatile derivatives. For derivatization, $1 \mathrm{~g}$ of petroleum ether extract was kept in the ultrasonic bath at room temperature until completely dissolved in $10 \mathrm{ml}$ hexane. Then 2 molar $\mathrm{KOH}$ was transferred to volumetric flask $(500 \mathrm{ml})$ and methanol solvent was added on it.

The dissolved petroleum ether extract was poured intoa separatory funnel and $50 \mathrm{ml}$ of $2 \mathrm{M}$ $\mathrm{KOH}$ solution was added to the extract. The hopper of the separatory funnel was closed, it was shaken several times by hand, and then its lid was opened and it was kept in this state for a while. About $0.5 \mathrm{ml}$ of the clear portion of the hexane phase remaining from the binary phase formed in the separatory funnel was used for analysis. The reaction was carried out at room temperature. GC-MS Spectrum was used for the analysis of volatile derivatives of fatty acids.

Agilent 5975 GC-MS system and Innowax FSC $(60 \mathrm{~m} \times 0.25 \mathrm{~mm}, 25 \mu \mathrm{m})$ polar column were utilised for GC-MS Analysis. The inlet temperature was regulated to $250{ }^{\circ} \mathrm{C}$. The carrier gas was Helium with a flow rate of $1 \mathrm{ml} / \mathrm{min}$. The oven temperature program was increased from $100{ }^{\circ} \mathrm{C}$ to $240{ }^{\circ} \mathrm{C}$ at a rate of $4{ }^{\circ} \mathrm{C} / \mathrm{min}$. and was implemented for $65 \mathrm{~min}$. in total by keeping at $240{ }^{\circ} \mathrm{C}$ for $30 \mathrm{~min}$. Mass Spectrum was arranged to be 70 Electron-volt and the mass range was arranged to be $35-450 \mathrm{~m} / \mathrm{z}$.

\section{Findings and discussion}

\subsection{Chemical analysis results of white chicory (Cichorium Intybus L.)}

The result of the chemical analyses performed (lignin, cellulose, ash, moisture and extractives) on the flour of the ground chicory (Cichorium intybus L.) plant is given in Table 1.It was determined that Lignin was at the rate of $14.9 \%$, Cellulose $30.0 \%$, Humidity rate $5.4 \%$, Ash rate $10.7 \%$, Fat rate $2.5 \%$ and extractives $6.8 \%$. Here, it was determined that Cellulose has the highest rate.

Table 1. Chemical analysis of Cichorium intybus L. Flour

\begin{tabular}{cc}
\hline Ingredient & \% boiling pointWeight \\
\hline Lignin & 14.9 \\
Cellulose & 30,0 \\
Humidity (\% Weight) & 5.4 \\
Ash(\%Weight) & 10.7 \\
Oil & 2.5 \\
Soxhlet extractives ( \% extracted, ashless and & 6.8 \\
dry weight) & \\
\hline
\end{tabular}




\subsection{Analysis results of oil obtained from milled Cichorium Intybus L. stem with GC-MS}

The results of the analysis of the oil obtained from 3 ground White Chicory (Cichorium intybus L.) stalk samples by GC-MS and the mean values of these values are shown in Tables 2 and 3. No statistical difference was observed between fatty acid compositions of the samples. When the fatty acid composition was examined, it was determined that linoleic (31.8\%) acid was the most detected fatty acid in percent. The total unsaturated fatty acids of the samples exceeded capacity of the saturatedones.

When the fatty acid compositions of the samples are examined, it is observed that the saturated and polyunsaturated fatty acids are in the forefront. Palmitic acid is the most detected by percentage among the saturated acids. When we examine the fatty acid composition of vegetable oils, palmitic acid and stearic acid are the most detected fatty acids among the saturated fats. Except for palm oil, stearic acid is found in vegetable oils at a higher rate by percentage. In chicory plant, palmitic acid was detected at a very high rate $(29.1 \%)$. This result is an important detail for chicory plant compared to other oil seeds and plants. [39].

Fatty acids containing 14 and lower carbon atoms were not detected in chicory plant. Monounsaturated fatty acid was not detected in any of the samples. Polyunsaturated fatty acids were detected at a level of approximately $59 \%$. Linolenic acid, which is also a polyunsaturated fatty acid, is the most detected fatty acid. Linolenic acid amounts of the samples were determined as $27.1 \%$.

Table 2. GC-MS Analysis results of oil obtained from White Chicory (Cichorium intybus L.) flour

\begin{tabular}{lccc}
\hline \multicolumn{1}{c}{ Fatty acids (\%) } & Sample 1 & Sample 2 & Sample 3 \\
\hline Palmitic acid $\left(\mathrm{C}_{16: 0}\right)$ & 29.07 & 29.22 & 29.14 \\
Stearic acid $\left(\mathrm{C}_{18: 0}\right)$ & 5.61 & 5.67 & 5.68 \\
Oleic acid $\left(\mathrm{C}_{18: 1}\right)$ & Could not be detected & Could not be detected & Could not be detected \\
Linoleic acid $\left(\mathrm{C}_{18: 2}\right)$ & 31.66 & 31.75 & 31.89 \\
Linolenic acid $\left(\mathrm{C}_{18: 3}\right)$ & 27.18 & 26.97 & 27.00 \\
Eicosanoic acid $\left(\mathrm{C}_{20: 0}\right)$ & 2.79 & 2.78 & 2.80 \\
Behenic acid $\left(\mathrm{C}_{22: 0}\right)$ & 3.68 & 3.61 & 3.50 \\
SFA (\%) & 41.15 & 41.28 & 41.11 \\
MUFA (\%) & 0 & 0 & 0 \\
PUFA (\%) & 58.84 & 58.72 & 58.89 \\
Total (\%) & 100 & 100 & 100 \\
\hline
\end{tabular}

SFA: Saturated fatty acid, MUFA: Monounsaturated fatty acid, PUFA: Polyunsaturated fatty acid. 
Table3. Mean Results of GC-MS Analysis of Oil Obtained from White Chicory (Cichorium intybus L.) Flour.

\begin{tabular}{lc}
\hline \multicolumn{1}{c}{ Fatty acids } & \% Weight Average \\
\hline Palmitic acid $\left(\mathrm{C}_{16: 0}\right)$ & 29.1 \\
Stearic acid $\left(\mathrm{C}_{18: 0}\right)$ & 5.7 \\
Oleic acid $\left(\mathrm{C}_{18: 1}\right)$ & 0 \\
Linoleic acid $\left(\mathrm{C}_{18: 2}\right)$ & 31.8 \\
Linolenic acid $\left(\mathrm{C}_{18: 3}\right)$ & 27.1 \\
Eicosanoic acid $\left(\mathrm{C}_{20: 0}\right)$ & 2.8 \\
Behenic acid $\left(\mathrm{C}_{22: 0}\right)$ & 3.6 \\
\hline
\end{tabular}

SFA: Saturated fatty acid, MUFA: Monounsaturated fatty acid, PUFA: Polyunsaturatedfatty acid.

As is known, these fatty acids are crucial fatty acids and it is required to take them into the body through nutrition. The fact that chicory plant is rich in terms of essential fatty acids reveals the nutritional value of the fat. In addition, the rates of Linoleic and Linolenic acids are also as important as the polyunsaturated fatty acid amount of any fat source. Although it is thought that being rich in terms of polyunsaturated fatty acid causes the decrease of oxidative stability, having high level of fatty acid content ensures a balance in terms of oxidative stability.

Earlier research on the composition of fatty acids in chicory plants, explored the fatty acid composition of some forage and meadow plants, including chicory. They identified Linolenic acid as the major fatty acid of the chicory plant [40]. In addition, they detected the most palmitic acid among saturated fatty acids. The researchers found monounsaturated fatty acids to be at a very low level. Their results are consistent with the results of our study. Our research's difference is that the percentage of Linolenic acid is much higher than our results. This may be due to many reasons such as soil conditions, variety differences and climatic conditions.

The results derived from another study on the fatty acid composition of the chicory plant were also very close to that in our study[40]. The fatty acid compositions of 9 different commercial chicory types were identified. As it was in accord with our study, palmitic acid is the most commonly detected fatty acid by percentage among the saturated acids of the samples. Palmitic acid levels of the samples were determined to be around the level of $22 \%$. As with our study, Linoleic acid is the most frequently detected fatty acid by percentage. When the results of these researchers are examined, the total percentage of linolenic and linoleic acid reaches a level of roughly $71 \%$. This result is higher than the results obtained from our study. The high amount can be explained by the variety and soil conditions. However, the level of palmitic acid, which is among saturated fatty acids, is high and the content of polyunsaturated fatty acid is higher than $50 \%$. These results are in concert with our study. Researchers have researched on fatty acid composition of some plants in Spain, including the chicory plant [41].

As it was in harmony with our study, palmitic acid is the most commonly detected saturated fatty acid. In a study on the fatty acid composition of some plants in Spain, including the chicory plant, palmitic acid is the most commonly detected saturated fatty acid, as in our study. Polyunsaturated fatty acids were also identified as major fatty acids. Stearic acid levels of the 
samples were also consistent with the results of our study. Another result that was consistent with our study was Behenic acid amount's being found to be more than $1 \%$. However, the results we have obtained are consistent with other publications in literature [42, 43]. In these studies, while palmitic acid was detected to be on a high level as saturated fat, the polyunsaturated fatty acids of the samples were determined to be major fatty acid.

The spectra obtained from GC-MS analysis of oils of White Chicory plant are presented in Figures 1, 2 and 3.

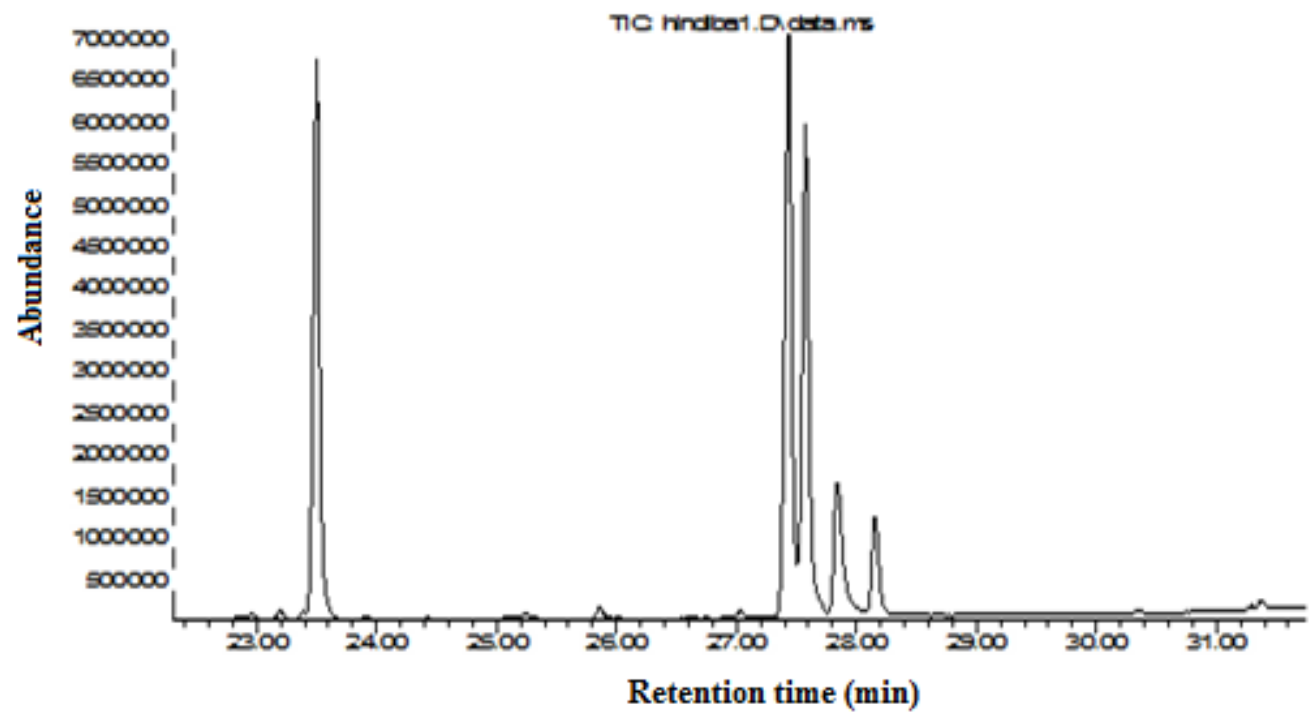

Figure 1. GC/MS spectrum of oil of Cichorium Intybus L. plant

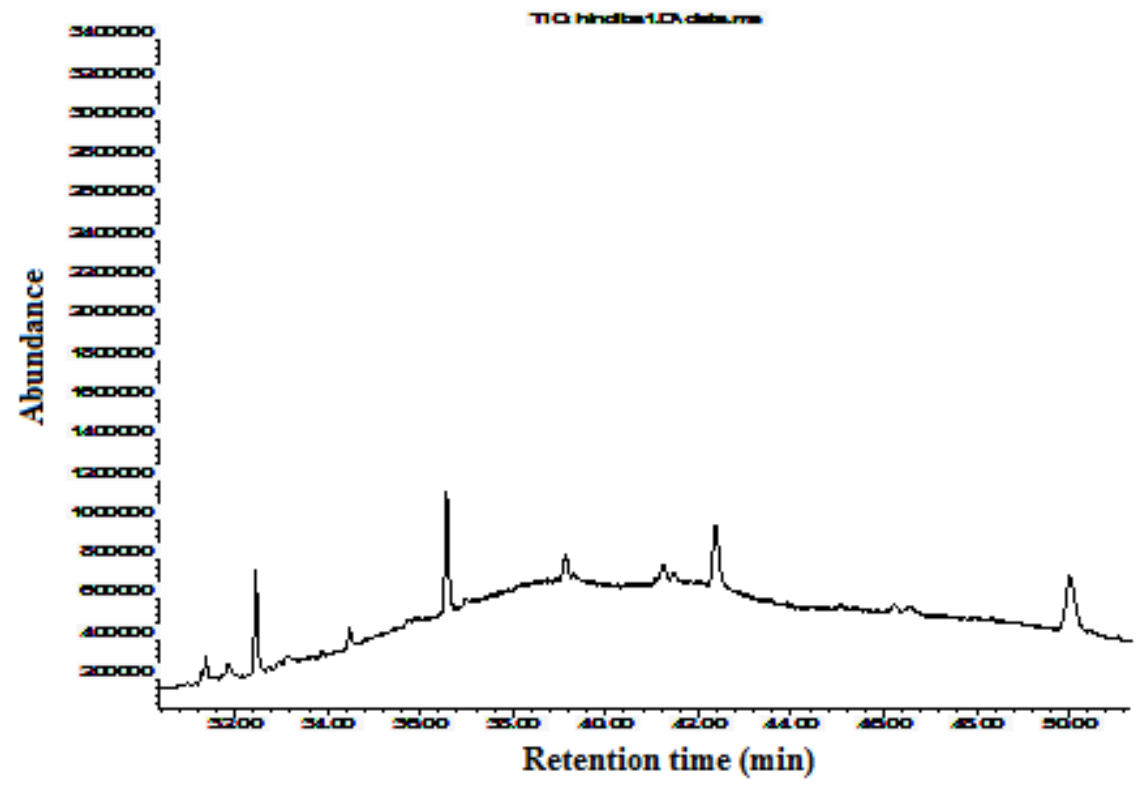

Figure 2. GC/MS spectrum of oil of Cichorium Intybus L. plant 


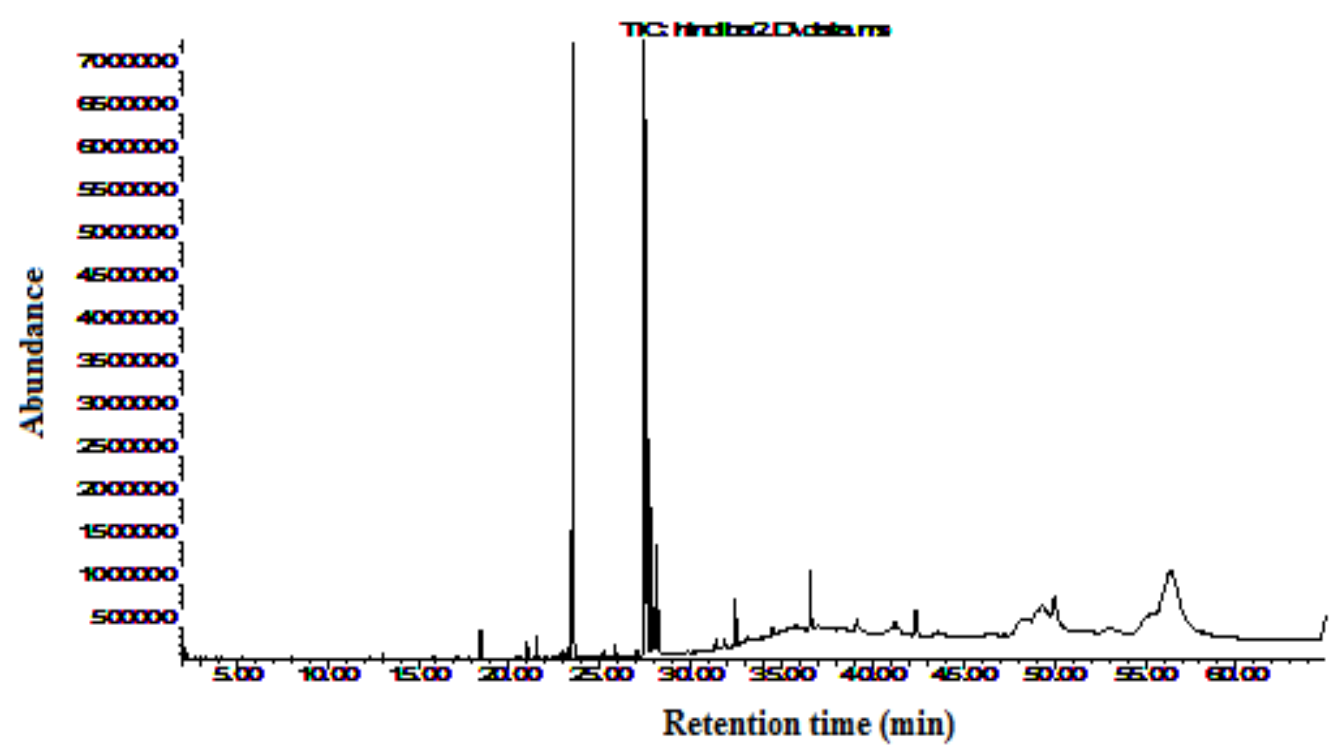

Figure 3. GC/MS spectrum of oil of Cichorium Intybus L. plant.

\section{Conclusion}

In this research, the chemical composition of the Cichorium intybus L. plant and the fatty acid composition of the oils extracted from the plant were examined. As a result of the study, it was determined that Cichorium intybus L. plant contains $14.9 \%$ lignin, $30.0 \%$ cellulose, $10.7 \%$ ash and $2.5 \%$ oil. As a result of the analysis made with GC-MS, it was found that the oil obtained from Cichorium intybus L. plant contains 31.8\% linoleic acid, 29.1\% palmitic acid, \% 27.1 linolenic acid; in addition, the total unsaturated fatty acids of the samples were found to be higher than saturated fatty acids. It was concluded that Cichorium intybus L. is a plant rich in essential fatty acids.

\section{References}

[1] Znidarcic, D., Ban, D.A., Sircelj, H., "Carotenoid and chlorophy 11 composition of commonly consumed leafy vegetables in Mediterranean countries", Food Chem. 129 (2011) : 1164-1168.

[2] Godts, C., Ceusters, J., Van Eylen, T., Francois, I., De Proft, M., "Characterisation of reddening in etiolated chicory leaves (Cichorium intybus L. var. foliosum)", Acta Horticulturae, (2012) : 936.

[3] Lekavičius, A., Lietuvos TSR Flora, eds. M. Natkevičaitė-Ivanauskienė, R. Jankevičienė and A. Lekavičius. Mokslas, Vilnius, 6 (1980): 179.

[4] Judžentienè, A., Būdienė J., "Volatile constituents from aerial parts and roots of Cichorium intybus L. (chicory) grown in Lithuania", Chemija. 19 (2008):25-28.

[5] Duke, J. A., "Handbook of energy crops", An electronic publication (1983). 
[6] Lavelli, V., Pagliarini, E., Ambrosoli, R., Zanoni, B., “Qualityof minimally processed red chicory (Cichorium intybus L.) evaluated by anthocyanin content, radical scavenging activity, sensory descriptors and microbial indices", Int. J. Food Sci.Tech. 44(2009) : 994-1001.

[7] Süntar, I., Akkola, EK., Kelesb, H., Yesiladac, E., Sarkerd, SD., Baykala, T., "Comparative evaluation of traditional prescriptions from Cichorium intybus L. for wound healing: stepwise isolation of an active component by in vivo bioassay and its mode of activity", Journal of Ethnopharmacology, PubMed 143(1) (2012) : 299-309.

[8] Carazzone, C., Mascherpa, D., Gazzani, G., Papetti, A., "Identification of phenolic constituents in red chicory salads (Cichorium intybus) by high-performance liquid chromatography with diode array detection and electrospray ionisation tandem mass spectrometry", Food Chem. 138 (2013) : 1062-1071.

[9] D'evoli, L., Morroni, F., Lombardi-Boccia, G., Lucarini, M., et al. "Red chicory (Cichorium intybus L. cultivar) as a potential source of antioxidant anthocyanins for intestinal health", Oxid. Med. Cell. Longev. 8 (2013).

[10] Paskovic, I., Bronic, J., Subotic, B., Pecina, M., et al. "Impact of synthetic zeolite fertilization on radicchio mineral composition and nutritive value", J. Food Agric. Environ. 11 (2013) : 498-502.

[11] Williams D. J., Edwards, D., Hamernig, I., Jian, L., et al. "Vegetables containing phytochemicals with potential anti-obesity properties: A review", Food Res. Int. 52 (2013) : 323-333.

[12] Piagentini, A.M., Mendez, J.C., Guemes, D.R., Pirovani, M. E., "Modeling changes of sensory attributes for individual and mixed fresh-cut leafy vegetables", Postharvest Biol. Tec. 38 (2005) : 202-212.

[13] Chevallier, A ., "The encyclopedia of medicinal plants. Dorling Kindersley", London, (1996).

[14] Grieve , M., ed. C. F. Leyel., “A modern herbal”, Dover Publications Inc., N. York, (1971).

[15] E. Launert, "Edible and medicinal plants", Hamlyn, UK. (1981).

[16] Triska, J., "The hamlyn encyclopaedia of plants”, Hamlyn, UK. (1975).

[17] Lust, J., "The herb book”, Bantam Books, Turonto and New York (1983).

[18] Uphof, J.C.Th., “Dictionary of economic plants”, New York, (1968).

[19] Foster, S., "A field guide to medicinal plants: Eastern and central North America". Houghton Mifflin, Boston, (1990).

[20] Petrovic, J ., Stanojkovic, A., Comic , Lj., and Curcic, S., "Antibacteriyal activitity of Cichorium intybus".Fitoterapia, 75(2004) : 737.

[21] Bischoff, T.A., Kelley, Ch.J.,Karchesy, Y., Laurantos, M., Nguyen-Dinh, Ph and Arefi, A.G., "Antimalarial activity of lactucin and lactucopicrin:Sesquiterpene lactones isolated from Cichorium intybus". J. Ethnopharmacol 95, 455, (2004).

[22] Seto, M., Miyase, T., Umehara, K., Ueno, A., Hirano, Y., and Otani, N., "Sesquiterpene lactones from Cichorium endivia L., and C. İntybus L. and cytotoxic activity". Chem. Pharmac. Bulletin 36(1988) : 2423.

[23] Pushparaj, P.N., Low, H. K., Manikandan, J., Tan, B. K. H., and Tan, C. H., “Antidiabetic effects of cichorium intybus instreptozotocin-induced diabetic rats", J. Ethnopharmacol 
111 (2007) : 430-434.

[24] Schmidt, B.M., Ilic, N., Poulev, A., Raskin, I. "Toxicological evaluation of a chicory root extract" Food Chem. Toxicol 45 (2007) : 1131-9.

[25] Şahin, H.T., "Kağıt ve kompozit ürünleri için hammadde kaynakları”, Süleyman Demirel Üniversitesi Orman Fakültesi, Orman Endüstri Mühendisliği Bölümü, 32260 Isparta, 43(2001):21-25.

[26] Coombs, J.A., "Strategy for commercial exploitation of biomass", Europe 2nd World Renewable Energy Congress, Pergamon Pres, 3 (1992) : 1192-1193.

[27] Demirbaş, A., "Yields of oil products from thermochemical biomass conversion processes", Energy Conversion \& Management, 39 (1996) : 685-690.

[28] Demirbaş, A., "Biomass resource facilities and biomass conversion processing for fuels and chemicals", Energy Conversion and Management, 42(2001): 1357-1378.

[29] Ganesh, A., Banerjee, R., "Biomass pyrolysis for power generation - A potential technology", Renewable Energy 22 (2001) : 9-14.

[30] Komiyama, H., Mitsumori, T., Yamaji, K., Yamada, K., “Assessment of energy systems by using biomass plantation”, Fuel, 80 (2001) : 707-715.

[31] Goyal, H.B., Seal, D., Saxseno, R.C., "Bio-fuels from thermochemical conversion of renewable resources: A review", Renewable and Sustainable Energy Reviews 12 (2008) : 504-517.

[32] Küçük, M. M., "Recent advances in biohass technology". Fuel Science and Technology International, 12(6)(1994) : 845-871..

[33] Ohlrogge, J. B., "Design of new plant products: Engineering of fatty acid metabolism", Plant Physiol. 104 (1994) : 821-826.

[34] Singh, S. P., Zhou, X. R., Liu, Q., Stymne, S., Green, A. G., "Metabolic engineering of new fatty acids in plants", Curr. Opin. Plant Biol. 8(2005) : 197-203.

[35] Pelliccia, F., Marazzi, G., Greco, C., Franzoni, F., et al., "Current evidence and future perspectives on n - 3 PUFAs", Int. J. Cardiol. 170 (2013) : S3-S7.

[36] Gogus, U., Smith, C., "n-3 Omega fatty acids: A review of current knowledge”, Int. J. Food Sci. Tech. 45 (2010) : 417-436.

[37] Lavelli, V., Pagliarini, E., Ambrosoli, R., Zanoni, B., "Quality of minimally processed red chicory (Cichorium intybus L.) evaluated by anthocyanin content, radical scavenging activity, sensory descriptors and microbial indices", Int. J. Food Sci. Tech. 44 (2009) : 994-1001.

[38] Çelebi, Ş., ve Karaca, H., "Yumurtanın besin değeri, kolesterol içeriği ve yumurtayı n3yağ asitleri bakımından zenginleştirmeye yönelik çalışmalar", Journal of the Faculty ofAgriculture, 37 (2) (2011) : 25-34.

[39] Clapham, W., Foster, J., Neel, J., Fedders. J., "Fatty acid composition of traditional and novel forages" J. Agric, Food Chem. 53(2005) : 10068-10073.

[40] Sinkovič, L., Demšar, L., Žnidarčič, D., Vidrih, R., "Fertilization impact on fatty acid profile of chicory and chicon plants ( Cichorium İntybus L.)”, Eur. J. Lipid Sci. Technol. 117 (2015) : 1659-1666.

[41] Morales, P., Ferreira, I., Carvalho, A., Sa'nchez- Mata, M., Ca'mara, M., Tardı'o, J., "Fatty acids profiles of some Spanish wild vegetables", Food Science and Technology International, 18 (3) (2012) : 281-290. 
[42] Sinkovič, L., Hribar, J., Vidrih, R., Žarko M., Žnidarčič, D., "Fatty acid compositıon of forced chicory (Cichorum IntybusnL.)”, Arch. Biol. Sci. 67 (2) (2015) : 647-653.

[43] Vardavas, C.,Majchrzak D., Wagner, K., Elmadfa, I., Kafatos, A., "Lipid concentrations of wild edible greens in Crete", Food Chem. 99(2006) : 822-834. 